\title{
EDUCAÇÃO AMBIENTAL: \\ ANÁLISE DA PERCEPÇÃO DOS \\ ALUNOS DO ENSINO \\ FUNDAMENTAL SOBRE A \\ QUALIDADE DA ÁGUA \\ CONSUMIDA NO MUNICÍPIO DE \\ BELÉM (PA)
}

João Ricardo Souza do Rêgo ${ }^{1}$

Resumo: Estudo que desvela a percepção de alunos de um colégio localizado no Município de Belém, capital do Estado do Pará, sobre a qualidade da água consumida diariamente em suas residências. Buscou-se, por meio de questionários, verificar a percepção ambiental dos estudantes a respeito da temática sobre qualidade e importância da água e comparar com os resultados da análise físico-química e microbiológica das águas coletadas, objetivando constatar se a qualidade da água percebida e relatada pelos alunos, corresponde com o enquadramento dos parâmetros dessa águas às normas de portabilidade. Por meio destes resultados foi possível revelar que os alunos possuem a percepção da importância da água de boa qualidade para os múltiplos usos humanos, conhecimento que se constitui essencial como estratégia de ensino em Educação Ambiental.

Palavras-chave: Recursos Hídricos; Percepção Ambiental; Qualidade da Água; Educação Ambiental. 


\section{Introdução}

O país vive um momento de crise hídrica, na qual muitas cidades sofrem com a falta deste recurso imprescindível à vida. É em virtude deste contexto de escassez vivenciada na contemporaneidade, que tem-se associado à definição de uso insustentável da água, a falta de consciência na sua utilização e negligência nos modos de gestão, as quais geram consequências, como a degradação da qualidade da água consumida diariamente pelos cidadãos, que acarretam implicações sociais diretas. A Educação Ambiental desponta como ferramenta eficiente na conscientização em prol da sustentabilidade, devendo ser compreendida como um processo contínuo que se materializa com vistas a desenvolver nos cidadãos a consciência ecológica necessária à vida no planeta.

Coimbra (2014) contribui ressaltando que o meio ambiente equilibrado ecologicamente é um direito fundamental dos seres humanos, de modo que todos têm o direito de desfrutar de seus recursos com qualidade e sem excessos, sendo inclusive fator preponderante para a promoção e realização da dignidade humana. Em vistas disso, a Educação Ambiental encontra-se prevista na Lei $n^{\circ}$ 9.795, de 27 de abril de 1999, a qual instituiu a Política Nacional de Educação Ambiental, com vistas a promover a democratização das informações ambientais, possibilitando aos cidadãos reconhecerem que têm direito a desfrutar de recursos ambientais de qualidade.

É justamente a partir de tal premissa que esta pesquisa foi empreendida, com o objetivo de desvelar a percepção de 62 (sessenta e dois) alunos do $6^{\circ}$ e $7^{\circ}$ ano do Ensino Fundamental de um Colégio localizado no município de Belém - Pará, acerca da qualidade da água consumida por estes diariamente. A partir da experiência vivenciada na pesquisa é possível afirmar que a Educação Ambiental em contexto escolar é um importante mecanismo para viabilizar atitudes sustentáveis, sendo capaz de mudar o panorama social atual, caracterizado pela crise hídrica e consumo água de má qualidade, fatores que configuram verdadeiros riscos ambientais. Além disso, a discussão em torno do tema "recursos hídricos" é uma forma de ampliar e sugerir ideias para melhorar o desenvolvimento dos professores em trabalhar com a temática, além de permitir o aprimoramento de métodos de ensino referente à Educação Ambiental, o que irá refletir na percepção e sensibilização dos alunos para a importância da temática e sua aplicação no âmbito escolar e familiar.

\section{Água e meio ambiente}

A relação entre população e meio ambiente tem sido marcada historicamente pela abordagem que salienta a relação entre volume populacional e disponibilidade de recursos ambientais (CARMO; DAGNINO; JOHANSEN, 2014). Não se pode pensar a sociedade como algo separado da natureza. A exemplo da água, esta exerce relevante papel por possuir grande importância para a vida, de tal modo que os conhecimentos sobre ela, em suas 
diferentes dimensões são de extrema relevância para a sobrevivência humana, a conservação da biodiversidade e para as relações entre os seres vivos e o ambiente natural (CARMO; DAGNINO; JOHANSEN, 2014; DIAS, 2004; MATURANA, 2002).

Estabelecido pela Organização das Nações Unidas para a Educação, a Ciência e a Cultura (UNESCO) como o Ano Internacional da Cooperação pela Água, objetivou-se em 2013 incentivar a sociedade, governos e empresas a adotarem atitudes e consciência sustentável sobre o acesso e uso da água. Alguns aspectos foram considerados pela UNESCO, tais como: somente $0,5 \%$ da água doce (em estado líquido) do planeta está acessível na superfície; cerca de $70 \%$ da água doce disponível no Brasil está na Bacia Amazônica; as indústrias do Brasil consomem cerca de 100 mil litros de água por segundo; cerca de $70 \%$ da água doce é consumida pelo setor agrícola (UNESCO, 2015). Segundo dados da UNESCO (2015), 70\% da disponibilidade de água no mundo é direcionada para a agricultura (Figura 1).

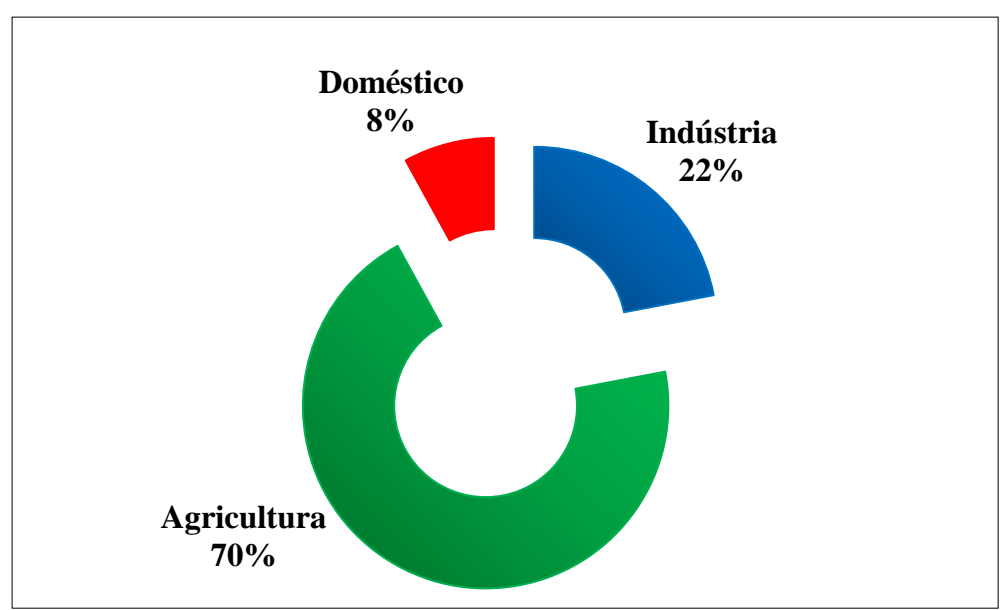

Figura 1: Distribuição do Consumo de água doce no Mundo.

Fonte: Organização das Nações Unidas para a Agricultura e Alimentação (FAO) (WWDR, 2015).

Segundo a lei da conservação de massas, o volume total de água na Terra não aumenta nem diminui, é sempre o mesmo. Desta forma, aproximadamente $70 \%$ da superfície do nosso planeta é composta por água, do qual, $97,5 \%$ deste total, é salgada. Da parcela de água doce, 68,9\% encontram-se nas geleiras, calotas polares ou em regiões montanhosas, $29,9 \%$ em águas subterrâneas, 0,9\% compõe a umidade do solo e dos pântanos e apenas $0,3 \%$ constitui a porção superficial de água doce presente em rios e lagos. A água doce não está distribuída uniformemente pelo globo. Sua distribuição depende essencialmente dos ecossistemas que compõem 0 território de cada país (WWDR, 2015).

Segundo o Programa Hidrológico Internacional da UNESCO, na América do Sul encontra-se $26 \%$ do total de água doce disponível no planeta e 
apenas $6 \%$ da população mundial, enquanto o continente asiático possui $36 \%$ do total de água e abriga $60 \%$ da população mundial (BRASIL, 2016).

A água potável é aquele líquido insípido, incolor e inodoro que se bebe e se usa para atender às necessidades básicas como banho, preparo de comida, limpeza. A agua doce na Terra - toda aquela cujo teor de sólidos totais dissolvidos (STD) é inferior a $1.000 \mathrm{mg} / \mathrm{l}$ - tem uma distribuição muito irregular, tanto no espaço quanto no tempo. Entretanto, as águas renováveis descargas médias de longo período dos rios do mundo de $43.000 \mathrm{~km} / \mathrm{ano}-$ são muito superiores às demandas totais de água da humanidade, da ordem de $6.000 \mathrm{~km}^{3} / \mathrm{ano}$, em que cerca de $70 \%$ é para irrigação, $20 \%$ para consumo industrial e 10\% para consumo doméstico (REBOUÇAS, 2015).

A água é o foco do desenvolvimento sustentável, pois influencia diretamente o futuro do ser humano, desde a segurança alimentar e energética até a saúde, logo, é necessário mudar as formas de avaliação, gerenciamento e uso desse recurso, em face da sempre crescente demanda e da elevada exploração das reservas subterrâneas (DIAS, 2016).

O aumento do número de pessoas sem acesso à água e saneamento em áreas urbanas está diretamente relacionado ao rápido crescimento da população no mundo em desenvolvimento e com a incapacidade (ou falta de vontade) dos governos locais e nacionais em fornecer infraestrutura necessária para promover o acesso à água potável e saneamento adequado às comunidades (IPEA, 2010).

A população em aglomerados habitacionais irregulares no mundo, quase 900 milhões até 2020, também é mais vulnerável aos impactos de eventos climáticos extremos. É possível, no entanto, melhorar o desempenho dos sistemas urbanos de abastecimento de água, ao mesmo tempo em que se promove sua expansão para atender às necessidades da população (UNESCO, 2016).

O ritmo acelerado do crescimento das cidades e as implicações provenientes da sua organização, sinalizam a urgência na efetivação de políticas públicas em saneamento para os municípios, em especial, no Norte do Brasil, que incluem: a gestão das águas pluviais, do esgoto e dos resíduos sólidos para garantir as demandas sociais e o consumo de água potável (TRINDADE; BORDALO, 2015).

Embora os problemas mais graves de poluição hídrica ocorram nas grandes metrópoles, não se pode desprezar os impactos causados em centros urbanos de pequeno e médio porte, além das zonas rurais (CAMARGO; BINI; SCHIAVETTI, 2017).

$\mathrm{Na}$ visão de Rebouças (2015) é certamente surpreendente que, embora a água tenha uma fórmula química básica simples, nunca tenha sido possível produzi-la artificialmente. O máximo que tem sido realizado, até agora, é ajustar a qualidade da água aos diferentes tipos de consumo, sendo feito principalmente por meio da determinação dos principais parâmetros que caracterizam as águas, que são: físico: temperatura, sabor, odor, cor, turbidez, Revbea, São Paulo, V. 13, № 4: 87-110, 2018. 
sólidos (em suspensão ou dissolvidos) e condutividade elétrica; químico: $\mathrm{pH}$, alcalinidade, acidez, dureza, cloretos, ferro e manganês, nitrogênio, fósforo, fluoretos, oxigênio dissolvido, matéria orgânica, demanda bioquímica e química de oxigênio, componentes inorgânicos e orgânicos; e biológico: bactérias coliformes e algas (BRASIL, 2006; UFV, 2011).

O transporte da água através dos sistemas distribuição, pode proporcionar a modificação da sua qualidade, fazendo com que o consumidor final receba em sua residência um recurso com parâmetros qualitativos diferentes daqueles do seu ponto de origem, a estação de tratamento. Tais mudanças podem ser causadas por variações físicas, químicas e biológicas ou por uma perda de integridade do sistema (BRASIL, 2006).

A água contém diversos componentes, provenientes do próprio ambiente natural ou que são incorporados a partir de atividades humanas. A partir de suas características físicas, químicas e biológicas é possível avaliar sua qualidade. Estas características sinalizam impurezas quando alcançam valores que não se enquadram àqueles estabelecidos para determinado uso (KUHNEN et al., 2017).

A Portaria no 2.914, de 12 de dezembro de 2011, que trata dos procedimentos de controle e de vigilância da qualidade da água para consumo humano e seu padrão de potabilidade, por exemplo, fixou o valor de $1,5 \mathrm{mg} \cdot \mathrm{L}^{-1}$ de flúor como o padrão de potabilidade para substâncias químicas que representam risco à saúde (BRASIL, 2011).

O relatório da UNESCO (2016) atribui a vários fatores a possível falta de água, entre eles, a intensa urbanização, as práticas agrícolas inadequadas e a poluição, que prejudica a oferta de água limpa no mundo. A organização estima que $20 \%$ dos aquíferos estejam sendo explorados acima de sua capacidade. Os aquíferos, que concentram água no subterrâneo e abastecem nascentes e rios, são responsáveis atualmente por fornecer água potável à metade da população mundial e é de onde provêm $43 \%$ da água usada na irrigação.

Estima-se que um bilhão de pessoas carecem de acesso a um abastecimento de água suficiente, definido como uma fonte que possa fornecer 20 litros por pessoa por dia a uma distância não superior a mil metros. Essas fontes incluem ligações domésticas, fontes públicas, fossos, poços e nascentes protegidos e alternativas, como a coleta de águas pluviais (WWDR, 2015).

A Conferência das Nações Unidas para a Água (1977), a Década Internacional de Abastecimento de Água Potável e Saneamento (1981-1990), a Conferência Internacional sobre Água e Meio Ambiente (1992) e a Cúpula da Terra (1992) tiveram seus debates voltados para este recurso vital. A segunda, em especial, ajudou cerca de 1,3 bilhão de pessoas, nos países em desenvolvimento, a obter acesso à água potável (ONU, 2017).

De acordo com as discussões ocorridas durante a Conferência Rio+20, o acesso à água potável para todos deve ser garantido e gerenciado de maneira inteligente para o desenvolvimento sustentável (UNESCO, 2015). A

revista brasileira educação ambiental 
expansão dos serviços de acesso à água potável de qualidade e de saneamento, diminuiria drasticamente a perda de vidas por doenças relacionadas com a água e aliviaria a escassez de recursos nos países em desenvolvimento.

Elevar o suprimento de água e de saneamento também pode aumentar o nível da educação, permitindo que mais crianças e adultos compareçam à escola em vez de passarem horas a cada dia coletando água. Isso também economizaria tempo, em termos de dias de trabalho, diminuindo a perda econômica geral em decorrência da falta de acesso à água potável de qualidade e ao saneamento básico (UNESCO, 2015).

No entanto, Victorino (2007) afirma que grande parte da água doce superficial do planeta encontra-se poluída, e essa situação irá perdurar enquanto não se mudar o pensamento egocêntrico da sociedade. As inúmeras campanhas a favor do meio ambiente têm tido pouca influência sob esse cenário, pois as pessoas não têm uma consciência ambiental, sabem da importância, porém não adotam no seu dia a dia. Cardoso et al. (2012) ressalta que a Educação Ambiental de jovens e crianças surge como uma ferramenta poderosa, pois possibilita a formação de futuros cidadãos ambientalmente conscientes.

\section{Metodologia}

Este estudo desenvolveu-se com 62 (sessenta e dois) alunos, em conjunto com seus responsáveis, do $6^{\circ}$ e $7^{\circ}$ ano do Ensino Fundamental do Colégio São Paulo, localizado no município de Belém, Pará.

Esta pesquisa é do tipo descritiva com abordagem quantitativa e qualitativa, ou seja, possui um enfoque misto. Segundo Alvarenga (2014), o enfoque de investigação quali-quantitativa, ou mista, é a união de ambos os paradigmas, denominando-se triangulação.

Neste sentido, um questionário semiestruturado, composto por questões semiabertas e fechadas, aplicado aos alunos, teve por objetivo revelar percepções a respeito da importância da água para múltiplas finalidades, qualidade de água, poluição dos corpos hídricos e atuação dos alunos enquanto cidadãos para preservação dos recursos.

A partir da adesão dos pais, algumas residências foram selecionadas de forma aleatória simples. Nestas, foram coletadas amostras da água, disponível nas torneiras, destinando-as à análise da sua qualidade a partir da determinação dos parâmetros físico-químicos e biológico. As amostras foram encaminhadas ao laboratório do Instituto Evandro Chagas, onde foram realizadas todas as análises.

Para os dados obtidos foram calculadas as médias e desvios-padrão, comparando-se os resultados obtidos nas análises físico-químicas com os valores máximos permissíveis (VMP) recomendados na portaria ํㅡㄹ 2.914/2011 (BRASIL, 2011). Os pontos de coleta das amostras de água foram distribuídos Revbea, São Paulo, V. 13, № 4: 87-110, 2018. 
nos bairros Pedreira, Marco, Umarizal, Fátima, Nazaré, São Brás, Canudos e Montese (Figura 2).

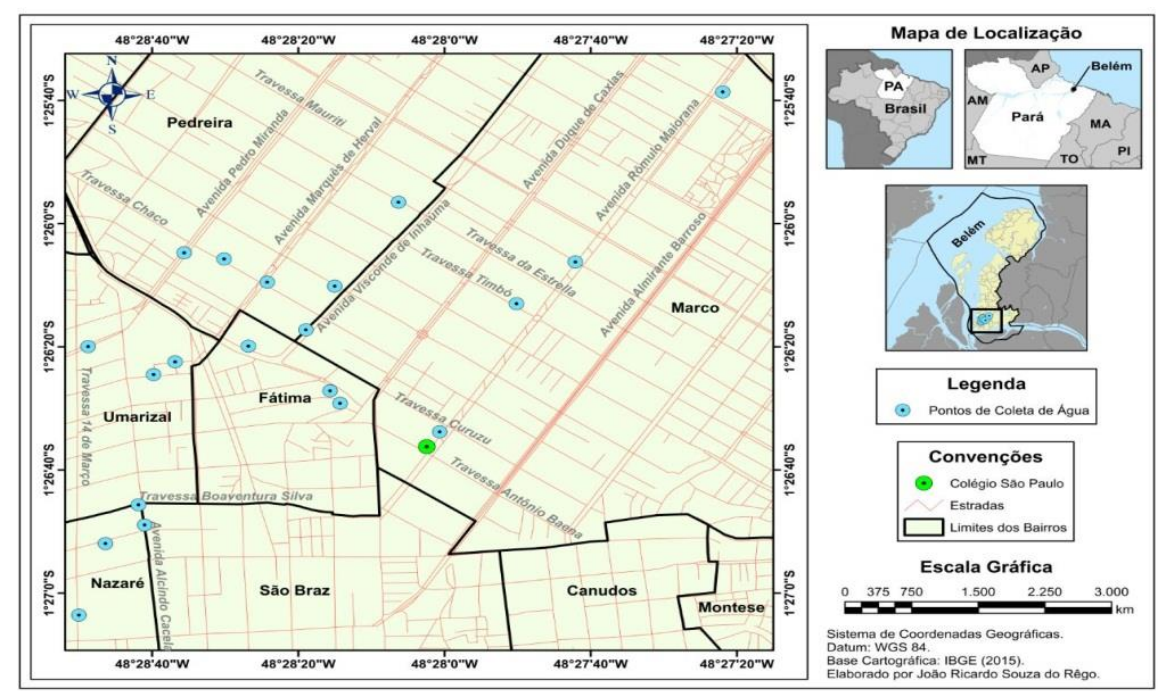

Figura 2: Mapa de distribuição dos pontos de coleta das amostras de água.

Fonte: Elaboração própria do autor (2017).

Neste estudo foi utilizado o teste Qui-quadrado de Pearson (amostras independentes) para tendência. Trata-se de um teste de hipótese que usa conceitos estatísticos para rejeitar ou não uma hipótese nula $\left(H_{0}=\right.$ Não existe tendência significativa entre as frequências).

É um teste estatístico para $n$ amostras cujas proporções das diversas modalidades estão dispostas em tabelas de frequência, sendo os valores esperados deduzidos matematicamente, procurando-se determinar se as proporções observadas nas diferentes categorias apresentam tendências.

Para realização do teste, foi adotado um nível de significância de $5 \%$, ou seja, se $p$-valor $<0.05$ aceita-se $\mathbf{H}_{\mathbf{1}}=$ Existe tendência significativa entre as frequências.

Desta forma, os dados coletados foram tabulados, interpretados, processados e analisados por meio de estatística descritiva e inferencial. A análise dos dados foram realizadas com auxílio de recursos de computação, por meio dos softwares Microsoft Excel e StatisticPackage for Social Sciences (SPSS) versão 22.0, todos em ambiente Windows 7. 


\section{Resultados e Discussão}

\section{Perfil sociodemográfico dos estudantes}

Verifica-se a partir da Tabela 1 que a maior frequência de alunos reside nos bairros de Fátima $(n=23 ; 41,82 \%)$ e Marco $(n=12 ; 21,82 \%)$. Quanto à renda familiar, observou-se que 30 alunos $(54,55 \%)$ tem renda familiar de até um salário mínimo.

Tabela 1: Distribuição dos alunos participantes da pesquisa, segundo o local de moradia e

\begin{tabular}{|c|c|c|c|}
\hline Bairro de Moradia & $\mathbf{n}$ & $\%$ & P-Valor ${ }^{(1)}$ \\
\hline Águas Brancas & 1 & 1,82 & \multirow{14}{*}{$<0.0001^{\star *}$} \\
\hline Bengui & 1 & 1,82 & \\
\hline Canudos & 2 & 3,64 & \\
\hline Castanheira & 1 & 1,82 & \\
\hline Condor & 1 & 1,82 & \\
\hline Decouville & 1 & 1,82 & \\
\hline Fátima & 23 & 41,82 & \\
\hline Jurunas & 1 & 1,82 & \\
\hline Mangueirão & 1 & 1,82 & \\
\hline Marambaia & 1 & 1,82 & \\
\hline Marco & 12 & 21,82 & \\
\hline Pedreira & 5 & 9,09 & \\
\hline São Braz & 1 & 1,82 & \\
\hline $\mathrm{NI}$ & 4 & 7,27 & \\
\hline \multicolumn{4}{|l|}{ Renda Familiar } \\
\hline Até $1 \mathrm{SM}$ & 30 & 54,55 & \multirow{5}{*}{$<0.0001^{*}$} \\
\hline 2 a 3 SM & 16 & 29,09 & \\
\hline 3 A 4 SM & 2 & 3,64 & \\
\hline 5 ou mais SM & 5 & 9,09 & \\
\hline $\mathrm{NI}$ & 2 & 3,64 & \\
\hline
\end{tabular}

Fonte: Dados resultantes da pesquisa (2017).

(1) Teste Qui-quadrado de Pearson para tendência ( $p$-valor $<0.05$ ).

** Valores Altamente significativos; *Valores Significativos; NS Valores Não Significativos.

$\mathbf{H}_{1}$ : Existe diferença significativa entre as frequências $(p<0.05)$.

$\mathrm{Na}$ Tabela 2 tem-se o perfil sociodemográfico e escolar dos alunos participantes da pesquisa, em que foi possível observar que as idades mais frequentes são entre 11 e 13 anos, sendo 16 (29,09\%) com 13 anos, 15 $(27,27 \%)$ com 11 anos e $13(23,64 \%)$ com 12 anos. A distribuição dos alunos entrevistados ocorreu nas turmas de $6^{\circ}$ ao $9^{\circ}$ ano, sendo $21(38,18 \%)$ do $6^{\circ}$ ano, $16(29,09 \%)$ do $7^{\circ}$ ano, $10(18,08 \%)$ alunos do $9^{\circ}$ ano e $8(14,55 \%)$ do $8^{\circ}$ ano. A maioria dos alunos é do turno vespertino $(n=41 ; 74,55 \%)$ e têm aulas de Educação Ambiental ( $n=51 ; 92,73 \%)$.

Os resultados referentes à relação renda dos responsáveis financeiros $x$ consumo de água inapropriada, concordou com os estudos de Alberto (2008), que destaca que as doenças provocadas por ingestão de água sem qualidade 
e a falta de saneamento básico, atingem, em sua maioria, as pessoas de baixa renda, ou seja, que ganham até um salário mínimo.

Com o objetivo de observar possíveis relações existentes entre nível de renda per capita e o consumo de água per capita, Carmo; Dagnino; Johansen (2014) apontam que a relação entre alta renda e elevado consumo de água não é homogênea para todas as capitais brasileiras.

Tabela 2: Distribuição dos alunos participantes da pesquisa, segundo o perfil sociodemográfico

\begin{tabular}{lccc}
\multicolumn{4}{c}{ e escolar } \\
\hline Idade do aluno & $\mathbf{n}$ & $\%$ & P-Valor \\
\hline 10 & 2 & 3,64 & \\
11 & 15 & 27,27 & \\
12 & 13 & 23,64 & $0.0005^{* *}$ \\
13 & 16 & 29,09 & \\
14 & 7 & 12,73 & \\
15 & 2 & 3,64 & \\
\hline Sexo dos Alunos & & & \\
\hline Feminino & 28 & 50,91 & \multirow{2}{*}{$0.8927^{\text {ns }}$} \\
Masculino & 27 & 49,09 & \\
\hline Turma dos Alunos & & & \\
\hline $6^{\circ}$ Ano & 21 & 38,18 & \\
$7^{\circ}$ Ano & 16 & 29,09 & $0.0546^{\text {ns }}$ \\
$8^{\circ}$ Ano & 8 & 14,55 & \\
$9^{\circ}$ Ano & 10 & 18,18 & \\
\hline Turno de Aulas & & & \\
\hline Matutino & 9 & 16,36 & \\
Vespertino & 41 & 74,55 & $<0.0001^{* *}$ \\
NI & 5 & 9,09 & \\
\hline Tem aulas de Educação Ambiental? & & & \\
\hline Sim & 51 & 92,73 & $<0.0001^{* *}$ \\
Não & 4 & 7,27 & \\
\hline
\end{tabular}

Fonte: Dados resultantes da pesquisa (2017).

(1) Teste Qui-quadrado de Pearson para tendência ( $p$-valor $<0.05$ ).

** Valores Altamente significativos; *Valores Significativos; NS Valores Não Significativos.

$\mathbf{H}_{1}$ : Existe diferença significativa entre as frequências $(p<0.05)$.

\section{Percepção ambiental}

A partir dos dados da Tabela 3, observou-se que, para maioria dos alunos $(\mathrm{n}=47 ; 85,45 \%)$, no bairro onde residem há falta de água. Conjuntamente a estes, 41 alunos (74,55\%) afirmaram que a água que chega até a residência não é de qualidade. Não há diferença significativa entre indivíduos que conhecem ou não o local que abastece a residência, de forma que 21 alunos $(38,18 \%)$ afirmaram que sim e $34(61,82 \%)$ afirmaram que não.

Quando questionados se nas proximidades de suas casas existem pontos de vazamento de água nas ruas, observa-se que 24 alunos $(43,64 \%)$ afirmaram que não e $10(18,18 \%)$ não sabem se há pontos de vazamento. $A$ maioria dos alunos concorda que a água do açude da cidade é utilizada para 
consumo humano ( $n=37 ; 67,27 \%$ ) e a maioria não sabe qual a distância da fossa com a torneira ( $\mathrm{n}=27 ; 49,09 \%)$.

Tabela 3: Distribuição dos alunos participantes da pesquisa, segundo o conhecimento sobre o Abastecimento de Água.

\begin{tabular}{|c|c|c|c|}
\hline Variável & $\mathbf{N}$ & $\%$ & P-Valor ${ }^{(1)}$ \\
\hline \multicolumn{4}{|c|}{ Em seu bairro ou em sua casa falta água? } \\
\hline Sim & 47 & 85,45 & \multirow{2}{*}{$<0.0001^{* *}$} \\
\hline Não & 8 & 14,55 & \\
\hline \multicolumn{4}{|c|}{ Você acha que a qualidade da água que chega até sua casa é boa? } \\
\hline Sim & 13 & 23,64 & \multirow{3}{*}{$<0.0001^{* *}$} \\
\hline Não & 41 & 74,55 & \\
\hline Não Sei & 1 & 1,82 & \\
\hline \multicolumn{4}{|c|}{ Você conhece o local (rio ou poço) que abastece sua casa? } \\
\hline Sim & 21 & 38,18 & \multirow{2}{*}{$0.0796^{\mathrm{ns}}$} \\
\hline Não & 34 & 61,82 & \\
\hline \multicolumn{4}{|c|}{ Próximo à sua casa existe pontos de vazamento de água nas ruas? } \\
\hline Sim & 21 & 38,18 & \multirow{3}{*}{$0.0516^{\mathrm{ns}}$} \\
\hline Não & 24 & 43,64 & \\
\hline Não Sei & 10 & 18,18 & \\
\hline \multicolumn{4}{|c|}{ A água do açude da minha cidade é utilizada para o quê? } \\
\hline Consumo humano & 37 & 67,27 & \multirow{6}{*}{$<0.0001^{* *}$} \\
\hline Despejo de esgotos & 4 & 7,27 & \\
\hline Lazer e turismo & 2 & 3,64 & \\
\hline Pesca & 2 & 3,64 & \\
\hline Outros & 2 & 3,64 & \\
\hline Não Sabe & 8 & 14,55 & \\
\hline \multicolumn{4}{|c|}{ Qual a distancia da fossa? (metros) } \\
\hline Até 4 metros & 2 & 3,64 & \multirow{5}{*}{$<0.0001^{* *}$} \\
\hline 5 a 10 metros & 13 & 23,64 & \\
\hline 11 ou mais metros & 12 & 21,82 & \\
\hline Não Possui & 1 & 1,82 & \\
\hline Não Sabe & 27 & 49,09 & \\
\hline
\end{tabular}

Fonte: Dados resultantes da pesquisa (2017).

(1) Teste Qui-quadrado de Pearson para tendência ( $p$-valor <0.05).

** Valores Altamente significativos; *Valores Significativos; NS Valores Não

Significativos.

$H_{1}$ : Existe diferença significativa entre as frequências $(p<0.05)$.

A Tabela 4 retrata a frequência de alunos participantes da pesquisa segundo o conhecimento destes sobre o tema Contaminação da Agua. Observou-se que a maioria $(n=54 ; 98,18 \%)$ significativa $(p<0.05)$ dos alunos possui conhecimento de que a contaminação de açudes, rios e mares pode causar doenças. Quando questionados se 0 ato de tomar banho em águas contaminadas pode causar doenças, a maioria afirmou que $\operatorname{sim}(n=53$; $96,36 \%)$. Para a maioria significativa $(p<0.05)$ dos alunos a ingestão de água contaminada também pode causar doenças $(n=54 ; 98,18 \%)$.

Sobre os tipos de doenças que podem ser adquiridos por meio da água contaminada, a maioria $(n=18 ; 32,73 \%)$ citou as doenças estomacais, seguido 
das verminoses $(n=14 ; 25,45 \%)$. Quando questionados de quem deve ser a responsabilidade de evitar que os recursos hídricos sejam contaminados, 50 alunos $(90,91 \%)$ responderam que este dever é de todos, tanto da população como dos governantes. Diferentemente dos resultados encontrados na pesquisa de Castoldi et al. (2009), onde verificou-se que, apesar de os alunos conhecerem os problemas ambientais existentes, estes possuem uma visão naturalista sobre os temais relativos ao Meio Ambiente, ou seja, percebem o ambiente como algo que não envolve o homem.

Tabela 4: Distribuição dos alunos participantes da pesquisa, segundo o conhecimento sobre a contaminação de Água

\begin{tabular}{|c|c|c|c|}
\hline Variável & $\mathbf{N}$ & $\%$ & P-Valor \\
\hline \multicolumn{4}{|c|}{ A contaminação de açudes, rios e mares podem causar doenças? } \\
\hline Sim & 54 & 98,18 & \multirow{2}{*}{$<0.0001^{\star *}$} \\
\hline Não Sei & 1 & 1,82 & \\
\hline \multicolumn{4}{|c|}{ Ao tomar banho em águas contaminadas pode-se adquirir alguma doença? } \\
\hline Sim & 53 & 96,36 & \multirow{2}{*}{$<0.0001^{\star *}$} \\
\hline Não Sei & 2 & 3,64 & \\
\hline \multicolumn{4}{|c|}{ Ao ingerir águas contaminadas pode-se adquirir alguma doença? } \\
\hline Sim & 54 & 98,18 & \multirow{2}{*}{$<0.0001^{* *}$} \\
\hline Não Sei & 1 & 1,82 & \\
\hline \multicolumn{4}{|c|}{ Que tipos de doenças a água contaminada pode causar? } \\
\hline Doencas estomacais & 18 & 32,73 & \multirow{7}{*}{$<0.0001^{* *}$} \\
\hline Verminoses & 14 & 25,45 & \\
\hline Febre, tifoide, hepatite, cólera. & 7 & 12,73 & \\
\hline Doenças de pele, diarreia & 6 & 10,91 & \\
\hline Cólera, Amebíase e etc. & 5 & 9,09 & \\
\hline Dores de cabeça & 1 & 1,82 & \\
\hline Não sei & 4 & 7,27 & \\
\hline \multicolumn{4}{|c|}{ De quem é o dever de evitar que os recursos hídricos seiam contaminados? } \\
\hline Da população & 1 & 1,82 & \multirow{3}{*}{$<0.0001^{* *}$} \\
\hline De todos & 50 & 90,91 & \\
\hline Do governo & 4 & 7,27 & \\
\hline \multicolumn{3}{|c|}{$\begin{array}{l}\text { Fonte: Dados resultantes da pesquisa }(2017) . \\
\text { (1) Teste Qui-quadrado de Pearson }(p-v a l o r<0.05) \text {. } \\
\star * \text { Valores Altamente significativos; }{ }^{*} \text { Valores Significativos; NS } \\
\text { Significativos. } \\
\mathbf{H}_{1} \text { : Existe diferença significativa entre as médias }(p<0.05) .\end{array}$} & Valores Não \\
\hline
\end{tabular}

Os resultados relativos à contaminação da água consumida demonstram que os alunos possuem conhecimentos fundamentados em preceitos ambientais, pois a maioria respondeu positivamente as questões que tratam do tema, indicando que a maioria sabe identificar uma água de má qualidade. Estes resultados estão concordando com a pesquisa de Alamino et al. (2005), realizada junto a alunos do ensino fundamental, na qual foi constatado que $91,6 \%$ dos alunos entrevistados demonstraram ter percepção e conhecimento sobre questões ambientais com foco no tema recursos hídricos, o que segundo o pesquisador é resultado de valores e concepções ambientais desenvolvidos na escola. 


\section{Análise da percepção da qualidade da água consumida \\ Resultado analítico}

No Brasil, a Portaria $n^{\circ}$ 2.914, de 12 de dezembro de 2011, do Ministério da Saúde (MS), dispõe sobre os procedimentos de controle e de vigilância de qualidade da água para consumo humano e seu padrão de potabilidade (BRASIL, 2011).

Segundo a Portaria, água potável é aquela que atende ao padrão de potabilidade e não oferece riscos à saúde. O padrão de potabilidade é definido como o conjunto de valores permitidos como parâmetros de qualidade da água destinada ao consumo humano (BRASIL, 2011). Os parâmetros que o definem, assim como seus valores limite, são continuamente revistos e atualizados em função da detecção de novos contaminantes e do uso de tecnologias mais recentes.

Assim como a resolução no $357 / 2005$ do Conselho Nacional do Meio Ambiente (CONAMA, 2005), a qual estabelece padrões para "classificação dos corpos de água e diretrizes ambientais para o seu enquadramento, bem como estabelece as condições e padrões de lançamento de efluentes, e dá outras providências".

Portanto, esta sessão tem o objetivo de apresentar os resultados das análises dos parâmetros físico-químicos da água consumida pelos alunos em suas residências, e compará-los com os padrões estabelecidos na resolução no 357/2005 do Conselho Nacional do Meio Ambiente (CONAMA, 2005) e na Portaria $n^{\circ} 2.914$ do MS, além de mostrar a variação de todos os parâmetros no decorrer dos pontos.

Neste sentido, a partir da adesão dos pais, algumas residências dos alunos foram selecionadas de forma aleatória simples. Nestas foram coletadas amostras para análise da qualidade da água servida nas torneiras, que foram encaminhadas ao Instituto Evandro Chagas que já apresenta um formulário padrão de análise contemplando um perfil físico-químico e microbiológico de análise.

Verifica-se na Tabela 5 que o pH médio da água consumida pelos alunos manteve-se abaixo dos parâmetros estabelecidos pela Resolução do CONAMA e pela Portaria do MS, que fixam o $\mathrm{pH}$ entre 6 e 9 , tanto em abril $(\mu=$ $5,6 \mathrm{pH} \approx 6 \mathrm{pH})$ como em junho $(\mu=5,7 \mathrm{pH} \approx 6 \mathrm{pH})$. O pH atingiu valor mínimo de 4,2 e máximo de 6,4 em abril e valor mínimo de 4,5 e máximo de 6,7 em junho. Além disso, esta diferença não se mostrou significativa $(p>0.05)$.

$\mathrm{O}$ termo $\mathrm{pH}$ representa a concentração de íons hidrogênio em uma solução. $\mathrm{Na}$ água, esse fator é de excepcional importância, principalmente nos processos de tratamento. $\mathrm{O}$ valor do $\mathrm{pH}$ varia de 0 a 14. Abaixo de $7(\mathrm{pH}<7)$ a água é considerada ácida e acima de $7(\mathrm{pH}>7)$, alcalina. Água com valore de $\mathrm{pH}=7$ é neutra (BRASIL, 2013). A Portaria no 2.914/2011 do Ministério da Saúde recomenda que o $\mathrm{pH}$ da água seja mantido na faixa de 6,0 a 9,5 no sistema de distribuição (BRASIL, 2011).

Revbea, São Paulo, V. 13, № 4: 87-110, 2018. 
A condutividade elétrica da água é a expressão numérica da capacidade da água em conduzir corrente elétrica. Depende das concentrações iônicas, da temperatura e indica a quantidade de sais existentes na coluna d'água, portanto, representa uma medida indireta da concentração de poluentes. Em geral, níveis superiores a $100 \mu \mathrm{S} / \mathrm{cm}$ indicam ambientes impactados (CETESB, 2008; SOEIRO et al., 2016).

Tabela 5: Estatística Descritiva das características físico-química e microbiológica das amostras de água consumida pelos alunos do colégio São Paulo nos meses de abril e junho de

\begin{tabular}{|c|c|c|c|c|c|c|c|c|c|}
\hline \multicolumn{10}{|c|}{2017} \\
\hline Variável & Mês & $\mathbf{n}$ & $\mathbf{n}^{\star}$ & Média $(\mu)$ & DP & Min & Max & P-Valor ${ }^{(1)}$ & Resultado \\
\hline \multirow{2}{*}{$\mathrm{pH}$} & Abril & 20 & 0 & 5,6 & 0,7 & 4,2 & 6,4 & \multirow{2}{*}{$0.843 n s$} & I \\
\hline & Junho & 20 & 0 & 5,7 & 0,9 & 4,5 & 6,7 & & I \\
\hline \multirow{2}{*}{$\begin{array}{l}\text { Condutividade } \\
(\mu \mathrm{S} / \mathrm{cm})\end{array}$} & Abril & 20 & 0 & 91,7 & 69,4 & 39 & 294 & \multirow{2}{*}{$0.044^{*}$} & C \\
\hline & Junho & 20 & 0 & 146,2 & 111,8 & 49 & 284 & & 1 \\
\hline \multirow{2}{*}{$\begin{array}{l}\text { Sólidos dissolvidos } \\
\text { totais (TDS) }\end{array}$} & Abril & 20 & 0 & 46,8 & 34,6 & 20 & 147 & \multirow{2}{*}{$0.043^{*}$} & C \\
\hline & Junho & 20 & 0 & 73,2 & 56,1 & 25 & 142 & & C \\
\hline \multirow{2}{*}{ Temperatura } & Abril & 20 & 0 & 22,2 & 0,8 & 19,5 & 23,1 & \multirow{2}{*}{$0.000^{\star *}$} & C \\
\hline & Junho & 20 & 0 & 25,7 & 0,7 & 23,7 & 26,6 & & C \\
\hline \multirow{2}{*}{ Cor Aparente } & Abril & 19 & 1 & 11,5 & 7,6 & 1,0 & 29,5 & \multirow{2}{*}{$0.515 \mathrm{~ns}$} & C \\
\hline & Junho & 20 & 0 & 10,1 & 6,0 & 1,0 & 21,0 & & C \\
\hline \multirow{2}{*}{ Cloreto } & Abril & 20 & 0 & 5,9 & 3,1 & 1,9 & 1,5 & \multirow[b]{2}{*}{-} & 1 \\
\hline & Junho & 20 & 0 & $<\mathrm{LD}$ & $<\mathrm{LD}$ & $<\mathrm{LD}$ & $<\mathrm{LD}$ & & - \\
\hline \multirow{2}{*}{ Dureza } & Abril & 20 & 0 & 2,8 & 0,5 & 1,3 & 3,7 & \multirow{2}{*}{$0.000^{* *}$} & I \\
\hline & Junho & 20 & 0 & 7,7 & 4,5 & 2,8 & 1,5 & & 1 \\
\hline \multirow{2}{*}{ Fluoreto } & Abril & 20 & 0 & 0,1 & 0,2 & 0,0 & 0,7 & \multirow{2}{*}{$0.035^{\star}$} & $\mathrm{I}$ \\
\hline & Junho & 20 & 0 & 0.00045 & 0.00179 & 0,0 & 0,008 & & 1 \\
\hline \multirow{2}{*}{ Nitrato } & Abril & 20 & 0 & 0,5 & 0,5 & 0,2 & 2,1 & \multirow{2}{*}{$0.002^{\star *}$} & C \\
\hline & Junho & 20 & 0 & 2,5 & 2,5 & 0,4 & 8,1 & & C \\
\hline \multirow{2}{*}{ Nitrito } & Abril & 20 & 0 & 0,003 & 0,002 & 0,001 & 0,010 & \multirow{2}{*}{$0.003^{\star *}$} & C \\
\hline & Junho & 20 & 0 & 0,013 & 0,014 & 0,000 & 0,047 & & C \\
\hline \multirow{2}{*}{ N-Amoniacal } & Abril & 20 & 0 & 0,1 & 0,2 & 0,0 & 0,8 & \multirow[b]{2}{*}{-} & $\mathrm{C}$ \\
\hline & Junho & 20 & 0 & $<\mathrm{LD}$ & $<\mathrm{LD}$ & $<\mathrm{LD}$ & $<\mathrm{LD}$ & & C \\
\hline \multirow{2}{*}{ Sulfato } & Abril & 20 & 0 & 3,1 & 6,4 & 0,0 & 24,0 & \multirow{2}{*}{$0.031^{*}$} & C \\
\hline & Junho & 20 & 0 & 10,6 & 13,2 & 0,0 & 30,0 & & C \\
\hline \multirow{2}{*}{ STS } & Abril & 20 & 0 & 0,9 & 0,9 & 0,0 & 2,5 & \multirow{2}{*}{$0.367 \mathrm{~ns}$} & - \\
\hline & Junho & 20 & 0 & 0,1 & 0,7 & 0,0 & 2,0 & & - \\
\hline \multirow{2}{*}{ Turbidez } & Abril & 20 & 0 & 0,8 & 0,9 & 0,0 & 2,5 & 0 718ns & 1 \\
\hline & Junho & 20 & 0 & 0,9 & 0,9 & 0,0 & 2,5 & $0.118 \mathrm{~ns}$ & 1 \\
\hline Salinidade & Abril & 20 & 0 & 0,043 & 0,034 & 0,020 & 0,140 & $0853 n s$ & - \\
\hline sallnidade & Junho & 20 & 0 & 0,041 & 0,034 & 0,010 & 0,140 & $0.853 \mathrm{~ns}$ & - \\
\hline
\end{tabular}

Fonte: Dados resultantes da pesquisa (2017).

(1) Teste T de Student ( $p$-valor <0.05).

** Valores Altamente significativos; *Valores Significativos; NS Valores Não Significativos.

$H_{1}$ : Existe diferença significativa entre as médias $(p<0.05)$.

$\mathrm{I}=$ Insuficiente/ $\mathrm{C}=$ Conformidade.

Verifica-se na Figura 3 que em abril a condutividade média da água $(\mu$ $=91,7 \mu \mathrm{S} / \mathrm{cm}$ ) manteve-se em conformidade com o indicado pelo CONAMA (2005) $(100 \mu \mathrm{S} / \mathrm{cm})$. Porém, no mês de junho o valor médio apresentou-se 
acima do esperado $(\mu=146,2 \mu \mathrm{S} / \mathrm{cm})$. Além disso, tanto em abril como em junho as amostras apresentaram valores máximos acima de $100 \mu \mathrm{S} / \mathrm{cm}$, sendo $294 \mu \mathrm{S} / \mathrm{cm}$ em abril e $284 \mu \mathrm{S} / \mathrm{cm}$ em junho, indicando que em geral a água consumida pelos alunos sofreu impactos indesejáveis, além disso, esta diferença se mostrou significativa $(p<0.05)$.

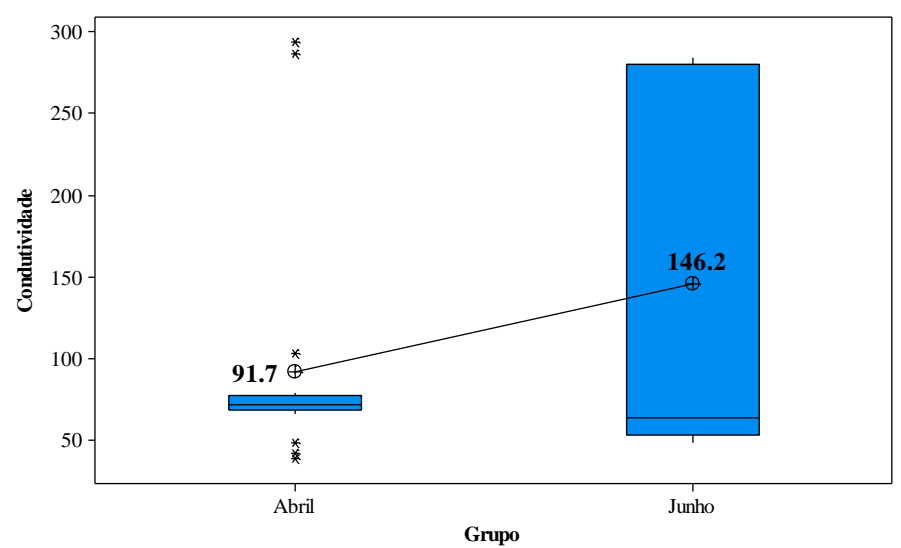

Figura 3: Avaliação segundo a condutividade elétrica em $\mu \mathrm{S} / \mathrm{cm}$.

Fonte: Elaboração própria do autor (2017).

Segundo Silva et al. (2015), sólidos dissolvidos totais (TDS) é o conjunto de todas as substâncias orgânicas e inorgânicas contidas num líquido sob formas moleculares, ionizadas ou micro granulares. É um parâmetro de determinação da qualidade da água, pois avalia o peso total dos constituintes minerais presentes na água, por unidade de volume. As substâncias dissolvidas envolvem o carbonato, bicarbonato, cloreto, sulfato, fosfato, nitrato, cálcio, magnésio, sódio e íons orgânicos, entre outros íons necessários para a vida aquática. Contudo, de acordo com Soeiro et al. (2016), quando presentes em elevadas concentrações, podem ser prejudiciais à saúde. A água com um TDS inferior a $500 \mathrm{mg} / \mathrm{L}$ cumpre as normas estabelecidas pelo CONAMA (2005) para a água potável.

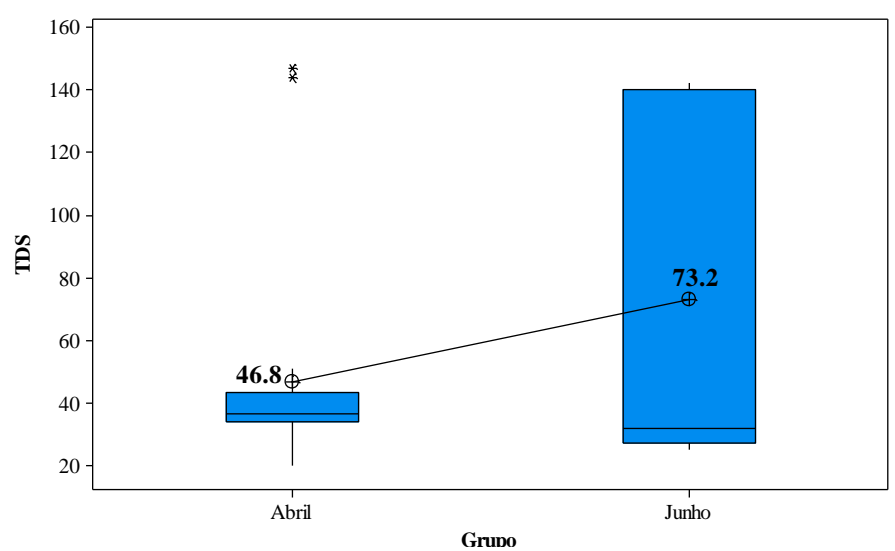


A Figura 4 mostra que o nível médio de TDS, tanto em abril $(\mu=46,8$ $\mathrm{mg} / \mathrm{L}$ ) como em junho ( $\mu=73,2 \mathrm{mg} / \mathrm{L}$ ), manteve-se em conformidade com os padrão estabelecidos para a água ser considerada em condições de consumo. Além disso, esta diferença se mostrou significativa $(p<0.05)$. Os valores máximos de TDS mantiveram-se abaixo de $500 \mathrm{mg} / \mathrm{L}$, cumprindo com as normas do CONAMA (2005).

A temperatura desempenha um papel crucial no meio aquático, condicionando as influências de uma série de variáveis físico-químicas. Em geral, à medida que a temperatura aumenta, de 0 a $30^{\circ} \mathrm{C}$, parâmetro como viscosidade, tensão superficial, compressibilidade, calor específico, constante de ionização e calor latente de vaporização diminuem, enquanto que a condutividade térmica e a pressão de vapor aumentam.

Neste sentido, verifica-se na Figura 5 que a temperatura da água consumida pelos alunos apresentou média igual a $22,2^{\circ} \mathrm{C}$ em abril e $25,7 \mathrm{em}$ junho, sendo um aumento de temperatura significativo $(p<0.05)$, porém manteve-se em conformidade com os parâmetros estabelecidos pelo CONAMA (2005).

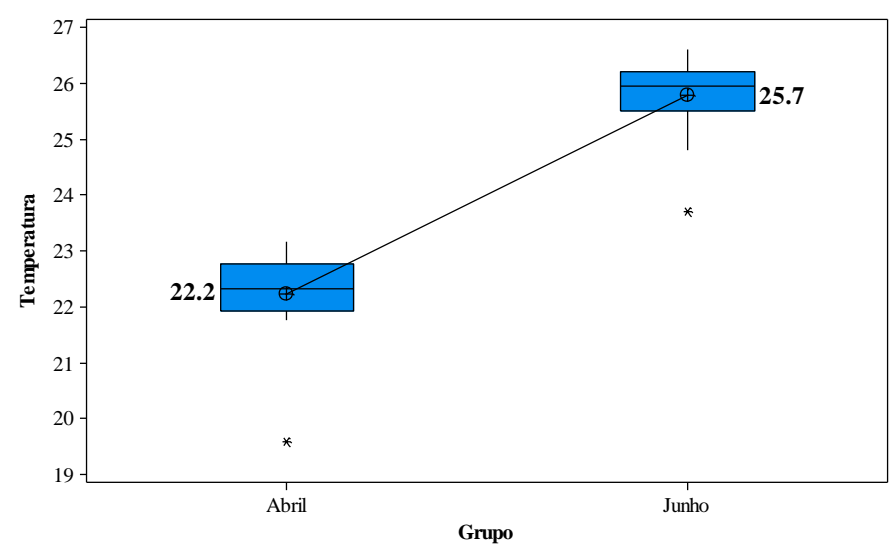

Figura 5: Avaliação segundo a temperatura em ${ }^{\circ} \mathrm{C}$. Fonte: Elaboração própria do autor (2017).

A cor aparente de uma amostra de água está associada ao grau de redução de intensidade que a luz sofre ao atravessá-la, a qual esta redução dáse por absorção de parte da radiação eletromagnética, devido à presença de sólidos dissolvidos, principalmente material em estado coloidal orgânico e inorgânico (REBOUÇAS, 2015).

Verifica-se na Figura 6 que a cor aparente da água consumida apresentou média igual a 11,5 uH em abril e 10,1 uH em junho, mantendo-se em conformidade com os parâmetros estabelecidos. 


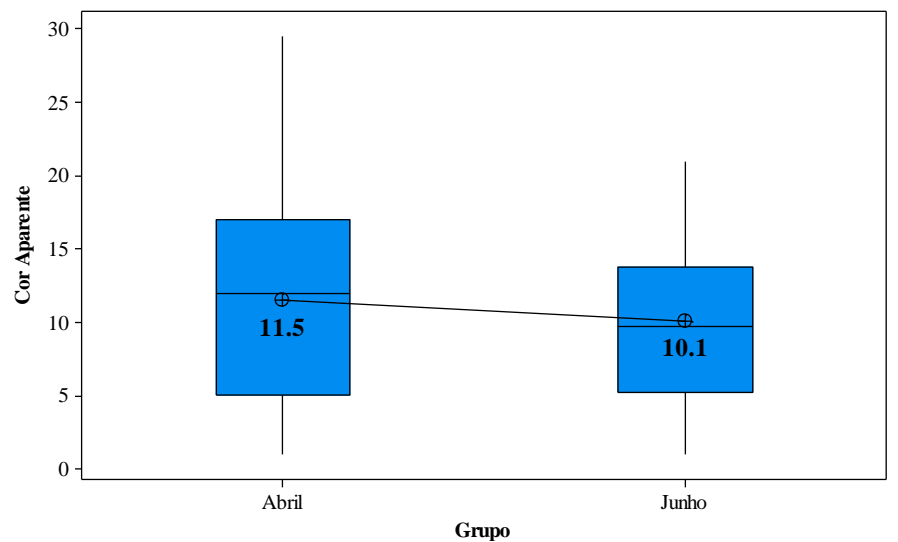

Figura 6: Avaliação segundo a cor aparente em uH. Fonte: Elaboração própria do autor (2017).

Porém, ao observarmos os valores máximos atingidos, verifica-se que a cor aparente alcançou 29,5 uH em abril e $21 \mathrm{uH}$ em junho, ultrapassando o limite de 15 (quinze) uH como padrão organoléptico para consumo humano. A Portaria MS no 2.914/2011 estabelece para cor aparente o valor máximo de 15 (quinze) uH como padrão organoléptico para consumo humano.

A Tabela 5 indicou que o nível médio de cloreto $(\mu=5,9)$ na água consumida pelos alunos manteve-se abaixo do estabelecido pela Portaria no 2.914/2011, que determina o teor de $250 \mathrm{mg} / \mathrm{L}$. Geralmente, os cloretos estão presentes em águas brutas e tratadas em concentrações que podem variar de pequenos traços até centenas de $\mathrm{mg} / \mathrm{L}$ estando presentes na forma de cloretos de sódio, cálcio e magnésio. A Portaria do Ministério da Saúde estabelece o teor de $250 \mathrm{mg} / \mathrm{L}$ como o valor máximo permitido para água potável. Os níveis de cloreto não puderam ser detectados em junho, pois estavam abaixo do limite de detecção.

O teor médio de dureza total na água consumida pelos alunos manteve-se abaixo do estabelecido pelas normas (qual?) (Figura 7), de forma que em abril atingiu teor médio de $2,8 \mathrm{mg} / \mathrm{L}$ e aumentou significativamente $(p<0.05)$ no mês de junho, atingindo teor de $7,7 \mathrm{mg} / \mathrm{L}$. Segundo Abdalla et al. (2010), a dureza total é calculada como sendo a soma das concentrações de íons cálcio e magnésio na água, expressos como carbonato de cálcio. A dureza de uma água pode ser temporária ou permanente. A Portaria do MS estabelece para dureza total o teor de $500 \mathrm{mg} / \mathrm{L}$ em termos de $\mathrm{CaCO}_{3}$ como o valor máximo permitido para água potável. 


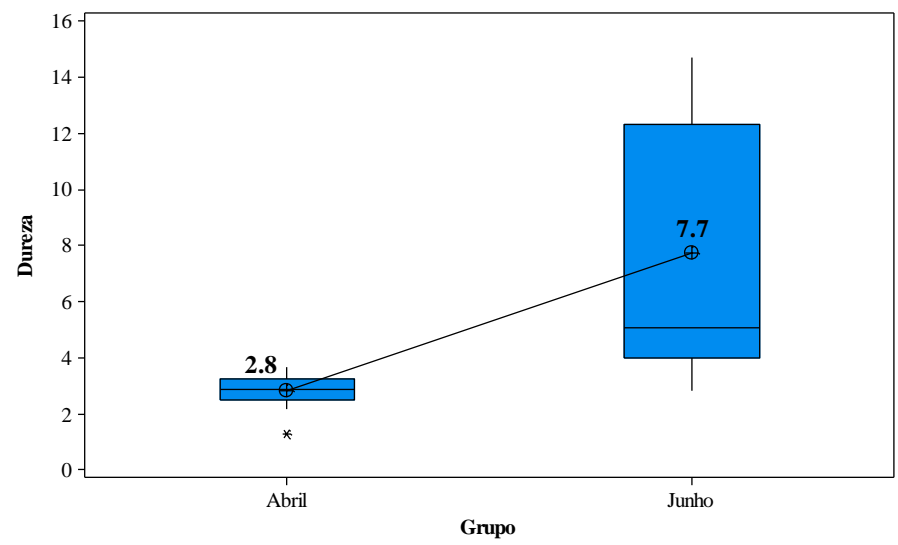

Figura 7: Avaliação segundo a dureza em mg/L.

Fonte: Elaboração própria do autor (2017).

Nas amostras de água consumida pelos alunos desta pesquisa, verifica-se que os níveis de fluoreto se mantiveram abaixo do estabelecido, com média equivalente a $0,1 \mathrm{mg} / \mathrm{L}$ em abril e $0.00045 \mathrm{mg} / \mathrm{L}$ em junho, conforme Figura 8.

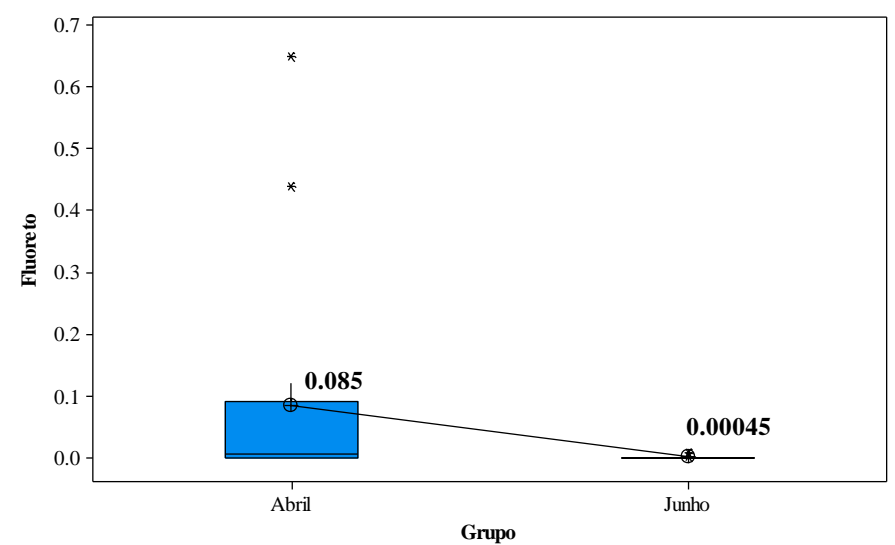

Figura 8: Avaliação segundo o teor de Fluoreto em mg/L. Fonte: Elaboração própria do autor (2017).

A ingestão necessária de fluoreto é de $1,5 \mathrm{mg} / \mathrm{dia}$, o que para um consumo de 1,2 a 1,6 litros de água por dia, corresponde a concentrações da ordem de 1,0 mg/L (BORDA, 2016; KUHNEN et al., 2017). Porém, a fluoretação das águas deve ser executada sob controle rigoroso, utilizando-se bons equipamentos de dosagem e implantando-se programas efetivos de controle de residual de fluoreto na rede de abastecimento de água, pois, de acordo com estudos desenvolvidos nos Estados Unidos, concentrações de fluoreto na água acima de $1,5 \mathrm{mg} / \mathrm{L}$, aumentam a incidência da fluorose dentária. A Portaria oำ2.914/2011 estabelece um valor máximo permitido para fluoreto de $1,5 \mathrm{mg} / \mathrm{L}$ na água potável. 
Na Figura 9 verifica-se que o teor médio de nitrato na água consumida pelos alunos é igual a $0,5 \mathrm{mg} / \mathrm{L}$ no mês de abril, com aumento significativo $(p<0.05)$ no mês de junho, quando atingiu o valor médio de $2,5 \mathrm{mg} / \mathrm{L}$, porém permaneceu abaixo do valor máximo permitido que é de $10 \mathrm{mg} / \mathrm{L}$. No caso do nitrito, o valor máximo permitido pela Portaria no 2.914/2011 do Ministério da Saúde é $1 \mathrm{mg} / \mathrm{L}$. Desta forma, verifica-se que os níveis de nitrito se mantiveram em conformidade com as normas, com média de $0,003 \mathrm{mg} / \mathrm{L}$ em abril e média de $0,013 \mathrm{mg} / \mathrm{L}$ em junho.

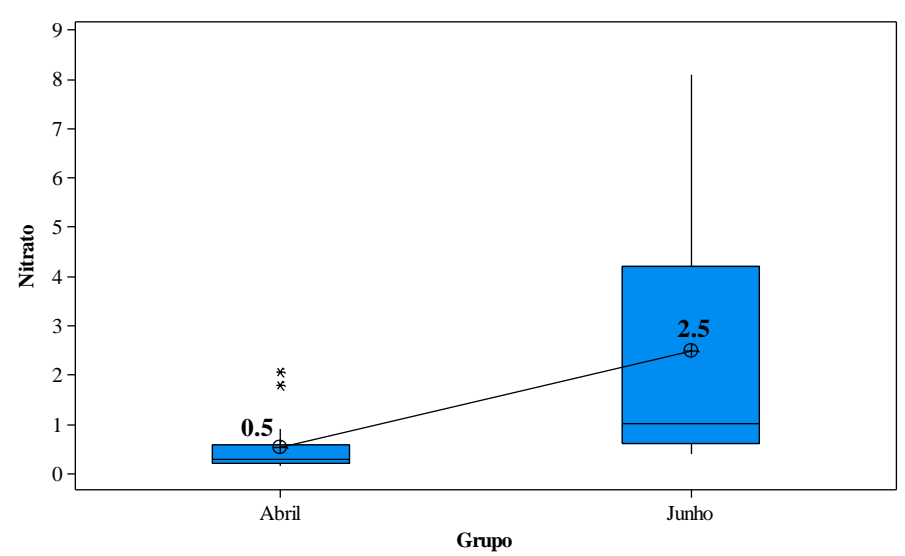

Figura 9: Avaliação segundo o teor de Nitrato em mg/L. Fonte: Elaboração própria do autor (2017).

O contaminante inorgânico de maior preocupação em águas subterrâneas é o íon nitrato $\left(\mathrm{NO}_{3}{ }^{-}\right)$, que normalmente ocorre em aquíferos de zonas rurais e suburbanas. $O$ nitrato em águas subterrâneas origina-se principalmente de quatro fontes: uso de fertilizantes com nitrogênio na agricultura, sejam inorgânicos ou de origem de esterco animal; cultivo do solo; esgoto humano depositado em sistemas sépticos e deposição atmosférica (BAIRD; CANN, 2011).

No caso do nitrogênio amoniacal, sua presença indica contaminação recente e pode estar relacionada à construção precária dos poços e falta de proteção do aquífero (PERPETUO, 2014), sendo $1,5 \mathrm{mg} / \mathrm{L}$ o valor máximo permitido pela Portaria oㅡ 2.914/2011 do Ministério da Saúde. O nível médio de nitrogênio amoniacal na água consumida pelos alunos manteve-se abaixo do valor máximo permitido, com média igual a $0,1 \mathrm{mg} / \mathrm{L}$ em abril. No mês de junho os níveis ficaram abaixo dos limites de detecção. O excesso de íon nitrato em água potável é preocupante por causar em recém-nascidos a síndrome do bebê azul, e em adultos, conforme pesquisas, pode ser responsável por causar câncer de estômago e aumentar a probabilidade de câncer de mama em mulheres (BAIRD; CANN, 2011).

A Figura 10 mostra que os teores de Sulfato se mantiveram em conformidade com os parâmetros estabelecidos, com valor médio igual a 3,1 $\mathrm{mg} / \mathrm{L}$ em abril, aumentando significativamente $(p<0.05)$ para $10,6 \mathrm{mg} / \mathrm{L} \mathrm{em}$ 
junho. O valor máximo desse elemento, permitido pela Portaria № 2.914/2011 do Ministério da Saúde, é de $250 \mathrm{mg} / \mathrm{L}$.

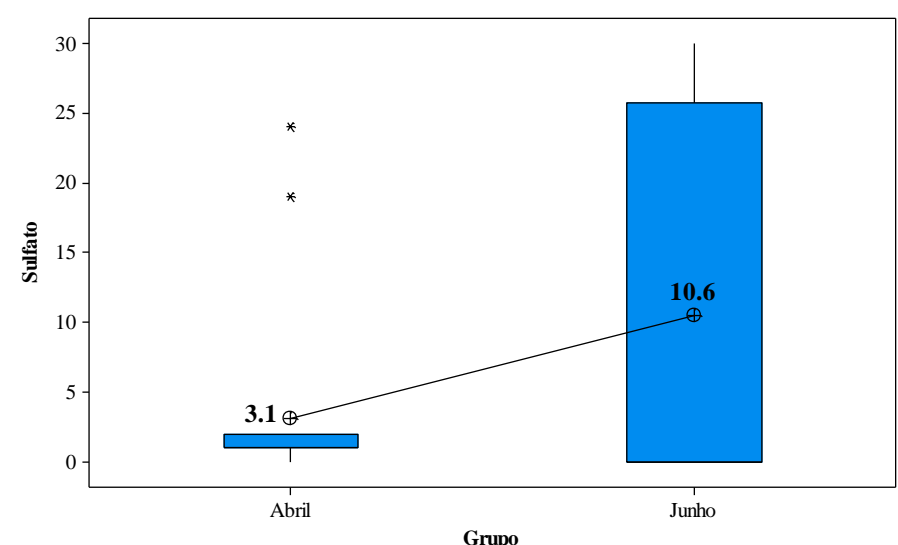

Figura 10: Avaliação segundo o teor de Sulfato em mg/L. Fonte: Elaboração própria do autor (2017).

Além da normalidade quanto aos parâmetros físico-químicos, a água potável não deve conter microorganismos patogênicos e deve estar livre de bactérias indicadoras de contaminação fecal. Como indicadores de contaminação fecal, são eleitas como bactérias de referência as do grupo Coliforme. Para a conformidade do padrão microbiológico de potabilidade é obrigatório a ausência de coliformes totais em $100 \mathrm{~mL}$ de amostra na saída do tratamento. No entanto, na Portaria no 2.914/2011, admite-se a presença de coliformes totais em apenas 01 amostra mensal para sistemas ou soluções coletivas que abastecem menos de 20.000 habitantes e em $5 \%$ das amostras mensais em sistemas ou soluções coletivas que abastecem mais de 20.000 habitantes. Ressalta-se que em ambas as situações não é permitida a presença de Escherichia coli na água para consumo humano.

Verifica-se na Tabela 6 que há registro de presença de coliformes totais em todas as amostras da pesquisa, tanto no mês de abril como no mês de junho. A presença de Escherichia coli foi observada em $45 \%$ das amostras de água no mês de abril e em $25 \%$ das amostras no mês de junho, o que confirma a falta de potabilidade da água.

Tabela 6: Análise Microbiológica das amostras de água consumida pelos alunos do colégio São Paulo nos meses de abril e junho de 2017.

\begin{tabular}{llcccc}
\hline \multirow{2}{*}{ Microbiológica } & \multirow{2}{*}{ Resultado } & \multicolumn{2}{c}{ Abril } & \multicolumn{2}{c}{ Junho } \\
\cline { 3 - 6 } & & $\mathrm{n}$ & $\%$ & $\mathrm{n}$ & $\%$ \\
\hline \multirow{2}{*}{ Coliformes Totais } & Presença & 20 & 100,0 & 20 & 100,0 \\
& Ausência & 0 & 0,0 & 0 & 0,0 \\
\hline \multirow{2}{*}{ Escherichia coli } & Presença & 9 & 45,0 & 5 & 25,0 \\
& Ausência & 11 & 55,0 & 15 & 75,0 \\
\hline
\end{tabular}

Fonte: Dados resultantes da pesquisa (2017).

Revbea, São Paulo, V. 13, № 4: 87-110, 2018. 
Resultados semelhantes, foram obtidos na pesquisa de Santos e Pereira (2015), a qual mostrou em parte das amostras de água no município de Bragança, no Pará, a presença de bactérias do grupo coliforme (indicador de contaminação fecal), $\mathrm{pH}$ de caráter ácido, presença de turbidez, elevadas temperaturas e baixo teor de oxigênio dissolvido no Rio Chumucuí. As coletas ocorreram também no mês de abril, período chuvoso, típico do inverno amazônico.

Diante destes dados, pode-se afirmar que a água quando não tratada adequadamente se torna uma importante via de transmissão de doenças, principalmente aquelas que afetam o trato intestinal, sendo capaz de agir como meio de cultura para microrganismos patogênicos e assim causar doenças àqueles que a ingerem. Considera-se, ainda, que o risco maior entre as crianças com menos de cinco anos, pois essas ainda não têm hábitos de higiene que possam evitar tais doenças.

\section{Relação entre a qualidade da água e a percepção dos alunos sobre o tema}

O estudo da percepção ambiental é de fundamental importância para que se possa compreender melhor as inter-relações entre o homem e o ambiente, suas expectativas, anseios, satisfações e insatisfações, julgamentos e condutas (FONSECA; ALMEIDA, 2017).

Desta forma, comparando-se os resultados apresentados nas Tabelas 5 e 6 e os indicados nas Tabelas 3 e 4, é observado que a má qualidade da água apontada na análise físico, química e microbiológica foi percebida e relatada pelos alunos quando questionados sobre a qualidade da agua consumida em suas residências.

Verifica-se que os resultados da análise do $\mathrm{pH}$, condutividade, cloreto, dureza, fluoreto e turbidez da água consumida, não estão em conformidade com o padrão estabelecido pelas normas para os parâmetros da água destinada ao consumo humano. Neste sentido, pode-se considerar, portanto, que os alunos possuem a percepção da importância da água de boa qualidade para os múltiplos usos humanos, principalmente para seu consumo, semelhante ao estudo realizado por Silva e Gomes (2013). Os autores destacam que é notória a existência de concepção relacionada à dependência da água, uma vez que os alunos reconheceram sua utilização para múltiplas atividades, como: consumo doméstico, agricultura, fonte de peixes e lazer e $71 \%$ dos alunos consideraram que a água não é de boa qualidade.

Nesse cenário, a abordagem dos temas voltados para a Educação Ambiental assume uma proposta interdisciplinar desenvolvida por meio de inúmeros conceitos e abordagens, objetivando a percepção da cidadania e a formação da consciência ambiental nos indivíduos, tendo na escola, um local adequado para sua realização através de uma pedagogia ativa e caracterizada pela participação de todos, sempre buscando integrar a ideia de conservação da natureza às práticas humanas.

Revbea, São Paulo, V. 13, № 4: 87-110, 2018. 


\section{Considerações Finais}

Os resultados obtidos indicam que o processo de Educação Ambiental desenvolvido pelo Colégio onde a pesquisa se realizou, tem fortalecido e estimulado a percepção ambiental por parte dos alunos no uso e na qualidade da água, pois a maioria dos alunos apontou de forma correta os principais fatores que contribuem para a má qualidade da água observada por meio das análises físico-química e microbiológica, Além disso, quando questionados sobre a qualidade da água que consomem, a maioria identificou esta como sendo de má qualidade, resultado que confirmado pela análise. Portanto, este estudo revelou que os discentes do referido Colégio têm conhecimento dos problemas relacionados à qualidade da água do município em que residem (Belém) e compreendem que também se constituem agentes causadores desses problemas.

Neste contexto, se reafirma a necessidade de incentivo à ampliação das práticas interdisciplinares de Educação Ambiental nas escolas de um modo geral, para que temas importantes presentes no cotidiano dos alunos sejam trabalhados de maneira crítica e participativa, proporcionando uma formação cidadã. Além disso, a luta contra práticas ambientais insustentáveis podem ser incorporadas pelas escolas e transcender para outros locais onde esses cidadãos em formação possam atuam como agentes de informações em suas famílias e rodas de amigos, objetivando minimizar os problemas decorrentes da poluição da água e destruição dos ambientes aquáticos, de forma a não comprometer o seu aproveitamento múltiplo e integrado.

\section{Referências}

ABDALLA, K. V. P. et al. Avaliação da dureza e das concentrações de cálcio e magnésio em águas subterrâneas da zona urbana e rural do município de Rosário-MA. In: XVI Congresso Brasileiro de Águas Subterrâneas e XVII Encontro Nacional de Perfuradores de Poços. Revista Águas Subterrâneas, 2010.

ALAMINO, A. L. M. et al. Qualidade da água: conservação, preservação e Educação Ambiental - conscientizando alunos de $5^{\text {a }}$ serie. Faculdade de Ciências e Tecnologia. Presidente Prudente: UNESP, 2005.

ALBERTO, C. C. Qualidade da água para consumo humano ofertada em escolas e comunidades rurais da região central do Rio Grande do Sul. 2008. Dissertação (Mestrado). Universidade Federal de Santa Maria. Rio Grande do Sul.

ALVARENGA, E. M. Metodologia de Investigação qualitativa e quantitativa. 2 ed. Asunción del Paraguay: A4 Diseños, 2014.

BAIRD, C.; CANN, M. Química Ambiental. Porto Alegre: Bookman, 2011. 
BORDA, A. A. Avaliação dos parâmetros físicos, químicos, biológicos e ecológicos do curso d'água do Rio Turvo (SP). 2016. 79 f. Dissertação de Mestrado. Universidade Estadual Paulista "Júlio de Mesquita Filho". 2016.

BRASIL. Ministério da Saúde. Portaria no 2.914, de 12 de dezembro de 2011. Dispõe sobre os procedimentos de controle e de vigilância da qualidade da água para consumo humano e seu padrão de potabilidade. Diário Oficial União. Acesso em: 14 abr. 2017.

BRASIL. Ministério da Saúde. Secretaria de Vigilância em Saúde. Vigilância e controle da qualidade da água para consumo humano/Ministério da Saúde, Secretaria de Vigilância em Saúde. - Brasília: Ministério da Saúde, 2006.

BRASIL. Ministério do Meio Ambiente. Água: um recurso cada vez mais ameaçado. $2016 . \quad$ Disponível em: http://www.mma.gov.br/estruturas/sedr proecotur/ publicacao/140 publicacao0 9062009025910.pdf Acesso em: 14 abr. 2017.

BRASIL. Ministério da Saúde. Portaria MS no 2.914, de 12 de dezembro de 2011. Dispõe sobre os procedimentos de controle e de vigilância da qualidade da água para consumo humano e seu padrão de potabilidade. Brasília: Diário Oficial da União, 2011.

CAMARGO, A. F. M.; BINI, L. M.; SCHIAVETTI, A. Avaliação dos impactos provocados pelas descargas de esgotos orgânicos em alguns corpos d'água no município de Rio Claro. OecologiaAustralis, v. 1, n. 1, p. 395-406, 2017.

CARMO, R. L.; DAGNINO, R. S.; JOHANSEN, I. C. Transição demográfica e transição do consumo urbano de água no Brasil. Revista Brasileira de Estudos de População, v. 31, n. 1, p. 169-190, 2014.

CASTOLDI, R.; BERNARDI, R.; POLINARSKI, C. A. Percepção dos problemas ambientais por alunos do ensino médio. Revista Brasileira de Ciência, Tecnologia e Sociedade, v. 1, n. 1, p. 56-80, 2009.

CETESB. Companhia Ambiental do Estado de São Paulo. Qualidade das águas interiores no Estado de São Paulo. Apêndice A. Significado Ambiental e Sanitário das variáveis de qualidade das águas e dos sedimentos e metodologias analíticas e de amostragem. São Paulo: CETESB, 2008.

COIMBRA, J.A.A. $O$ outro lado do meio ambiente. 6 ed. São Paulo: Millennium, 2014.

CONAMA. Conselho Nacional de Meio Ambiente. Resolução no 357, de 17 de março de 2005. 2005. Disponível em: <http://www.mma.gov.br/port/conama llegiabre.cfm?codlegi=459> Acesso em: 18 jan. 2018.

DIAS, G. F. Educação Ambiental: princípios e práticas. São Paulo: Gaia, 2004.

DIAS, H. Educação e Ambiente: Um percurso de aprendizagem sobre a interdependência entre a água e o mundo verde. 2016. Dissertação de Mestrado (Educação). Escola Superior de Educação. 2016.

Revbea, São Paulo, V. 13, № 4: 87-110, 2018. 
FONSECA, G. B.; ALMEIDA, V. L. a percepção ambiental de alunos do ensino médio da escola estadual ministro João Paulo dos Reis Veloso, DouradosMS. ANAIS DO SEMEX, n. 9, 2017.

IPEA. Brasil em Desenvolvimento: Estado, planejamento e políticas públicas. Brasília: Ipea - Instituto de Pesquisa Econômica Aplicada, 2010.

KUHNEN, M. et al. Qualidade da água tratada: avaliação dos teores de flúor em 10 anos de heterocontrole no município de Lages, Santa Catarina, Brasil. Vigilância Sanitária em Debate: Sociedade, Ciência \& Tecnologia, v. 5, n. 1, p. 91-96, 2017.

MATURANA, H. Cognição, Ciência e Vida cotidiana. Belo Horizonte. UFMG, 2002.

ONU. Organização das Nações Unidas. A ONU e a água. Disponível em: <https://nacoesunidas.org/acao/agua/> s. s. Acesso em: 15 abr. 2017.

PERPETUO, E. A. Parâmetros de caracterização da qualidade das águas e efluentes industriais. São Paulo: CEPEMA-USP, 2014.

REBOUÇAS, A. Uso inteligente da água. Escrituras Editora e Distribuidora de Livros Ltda., 2015.

SANTOS, R. A. M.; PEREIRA, L. C. C. Qualidade da água para consumo humano no município de Bragança-PA, Amazônia costeira. In: CONGRESSO BRASILEIRO DE GESTÃO AMBIENTAL, 6. Porto Alegre. Anais ... Porto Alegre: UFRGS. 2015.

SILVA, A. P. C; GOMES; S. P. Percepção dos alunos do ensino fundamental em relação ao uso da água em Santa Cruz-RN. Pós-graduação Lato Sensu em Educação Ambiental e Geografia do Semiárido na Modalidade a Distância Instituto Federal do Rio Grande do Norte. Revista Educação Ambiental. 2013.

SILVA, J. C. et al. Avaliação de salinidade, condutividade elétrica, sólidos totais dissolvidos e potencial de oxidação/redução das águas superficiais do rio Maratauíra-Abaetetuba-PA. In: Encontro de profissionais da Química da Amazônia, 14, 2015, Belém-Pará.

SOEIRO, R. K. S. et al. Relação entre a origem costeira de Macrobrachiumamazonicum e o nível de salinidade na larvicultura. Boletim do Instituto de Pesca, v. 42, n. 3, p. 691-703, 2016.

TRINDADE, A. B.; BORDALO, C. A. L. Indicadores dos serviços/rede de abastecimento de água potável nos municípios de Belém e Ananindeua - PA: considerações para elaboração da cartografia. Revista Nacional de Gerenciamento de Cidades, v. 03, n 18, 2015.

UFV. Qualidade da Água. Disponível em: http://www.ufv.br/dea/lqa/ qualidade.htm. Acesso em: 14 abr. 2011. 
UNESCO. Organização das Nações Unidas para a Educação, a Ciência e a Cultura. Gestão mais sustentável da água. 2015. Disponível em: http://www.unesco.org/new/pt/brasilia/about-this-office/single-

view/news/urgent need to manage water more sustainably says un report/ Acesso em: 12 abr. 2017.

UNESCO. Organização das Nações Unidas para a Educação, a Ciência e a Cultura. Relatório Mundial das Nações Unidas sobre Desenvolvimento dos Recursos Hídricos. 2016. Disponível em: http://www.unesco.org/fileadmin/ MULTIMEDIA/HQ/SC/images/. Acesso em: 13 abr 2017.

VICTORINO, C. J. A. Planeta água morrendo de sede: uma visão analítica na metodologia do uso e abuso dos recursos hídricos. Porto Alegre: EDIPUCRS, 2007.

WWDR. Relatório Mundial das Nações Unidas sobre Desenvolvimento dos Recursos Hídricos: Água para um Mundo Sustentável. 2015. Online. Disponível em: http://www.unesco.org/new/fileadmin/MULTIMEDIA/HQ/SC/. Acesso em: 17 jun. 2017. 